\title{
ALÉM DA ÓBVIA, EXISTIRÁ OUTRA QUÍMICA QUE A COMPLEMENTA, NEM QUE SEJA PELA ATRAÇÃO OU PELA REAÇÃO ÀS COISAS MAIS PROSAICAS E MUNDANAS DA VIDA
}

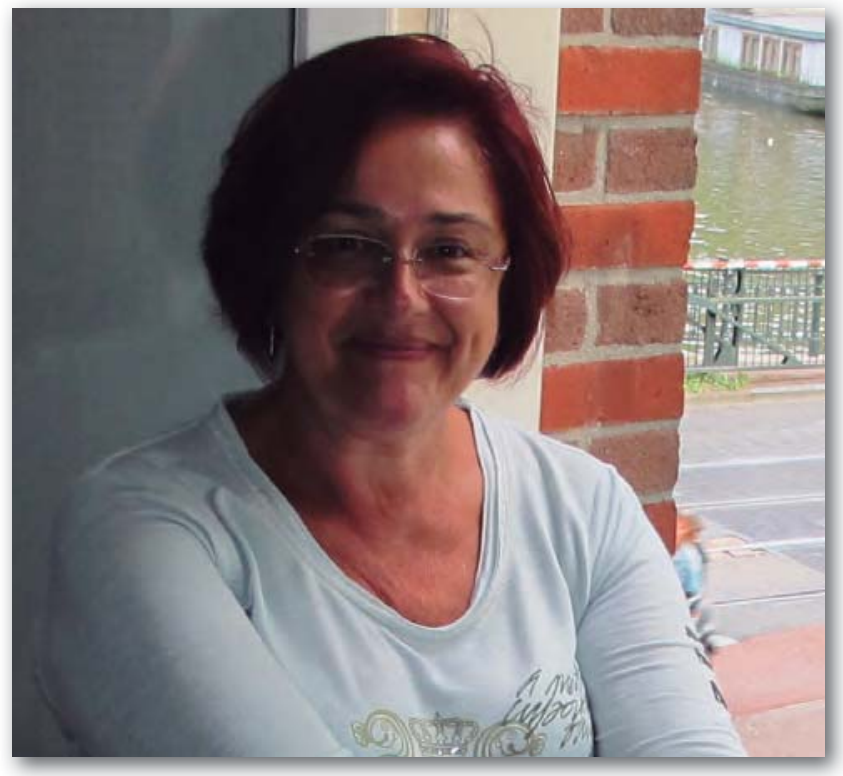

Maria Paula Robalo

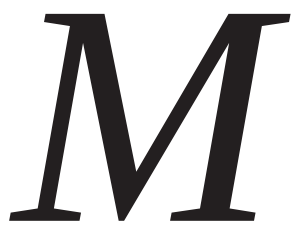

aria Paula Robalo é Professora Coordenadora no ISEL (Instituto Superior de Engenharia de Lisboa) e investigadora no Centro de Química Estrutural, Instituto Superior Técnico da Universidade de Lisboa. Licenciou-se em Química na Faculdade de Ciências da Universidade de Lisboa em 1986 tendo aí também obtido o Doutoramento em Química/Química Inorgânica em 1993 sob a orientação da Professora Maria Helena Garcia. Durante cerca de uma década foi Professora Auxiliar e mais tarde Professora Associada no Departamento de Química da Universidade de Évora, onde coordenou a área científica de Química Orgânica e desempenhou cargos de gestão universitária. Em 2002 ingressou na Área Departamental de Engenharia Química do ISEL e desde aí tem coordenado a área científica de Química Inorgânica e participado ativamente em vários cargos de gestão. Tem estado envolvida em vários projetos de investigação com financiamento nacional, em redes europeias $e$ em ações COST. É autora de cerca de 50 publicações. Os seus interesses de investigação incluem áreas como o design, síntese e caracterização espetroscópica de complexos de metais de transição com propriedades de ótica não linear (NLO), fotocrómicas ou como agentes anti-tumorais e a caracterização eletroquímica do comportamento redox de complexos metálicos, incluindo estudos de interação com biomoléculas. Mais recentemente, tem-se centrado no desenvolvimento de métodos de síntese de diversas classes de compostos heterocíclicos aromáticos com potencial atividade biológica recorrendo a processos mais sustentáveis como a biocatálise utilizando oxidorredutases.

\section{*** Entrevista ***}

Que livro, canção, filme, teatro ou outra atividade performativa que mais a hipnotizaram até hoje? Porquê?

Filmes...atualmente não vou muito ao cinema e com o tempo vamo-nos desabituando, mas...o primeiro que me vem mesmo à cabeça como um dos eleitos é o Cinema Paradiso pela capacidade que teve de me deslumbrar e arrebatar.

Livros: muitos..., não consigo propriamente designar um sem correr o risco de estar a ser injusta para muitos outros. Dos autores portugueses, vários me fascinaram (Eça, Camilo, Fernando Pessoa, José Saramago e mais recentemente Domingos Amaral, Miguel Esteves Cardoso), também Agatha Christie teve o seu período com o magnífico Hercule Poirot e das leituras mais recentes relembro Isabel Allende, Vargas Llosa, Carlos Ruiz Záfon, Julia Navarro, enfim... muitos.

As minhas preferências literárias foram variando ao longo da vida desde o tempo em que perdia umas boas horas de sono para acabar um livro e conhecer o fim da história até hoje, em que outras literaturas científicas me deixam pouco mais do que alguns minutos para ler umas páginas de outros livros. Mas continuo teimosamente a tentar não perder o hábito!

Quanto a música também tenho um gosto muito eclético. Dependendo do estado de espírito, tanto posso apreciar uma boa ária de ópera como uma banda rock (Queen, Pink Floyd, Scorpions ou os mais recentes Muse) ou outras paragens mais calmas como os sons cubanos dos Buena Vista Social Club, as mornas da Cesária Évora sem esquecer a música portuguesa. E mesmo nas outras vertentes musicais, há sempre uma ou outra música (cujo nome do autor e da canção às vezes nem sei) eleita pela capacidade de me despertar emoções...

E pensando em outras atividades performativas não posso deixar de lembrar os fantásticos espetáculos do Cirque du Soleil, também pela coragem na aposta diferenciadora.

Quais as plantas e os metais da sua preferência? Que atributos lhes confere?

Metais: sem dúvida o ferro e o ruténio pela presença assídua que têm tido ao longo de toda a minha vida científica. São metais de transição, velhos conhecidos, mas sempre prontos a gerar novas estruturas, novas cores, novas propriedades e sempre com a capacidade de nos surpreender!

Pensando em plantas, vou criando as minhas paixões pela exuberância das cores e pelos aromas: a alfazema pela cor e pelo efeito relaxante, a papoila pela beleza efémera e a orquídea pelo exotismo são alguns exemplos. 
Que atividades do quotidiano mais gosta de fazer e coordenar? E aquelas para as quais prefere cada vez mais ir ligando menos?

Gosto de todas as situações que envolvem criatividade, seja para as executar ou para as coordenar. Gosto dessa dualidade de ensinar e investigar (ou, por outras palavras, aprender com as novas situações) pois permite-nos renovar. Essa é uma das razões porque o meu quotidiano se torna menos rotineiro. Claro que nem sempre é fácil conciliar todas as vertentes, incluindo as familiares, sem aplicar o fator "desmultiplicar”. E nem todas as tarefas são igualmente motivantes, para mim as burocráticas são sempre aquelas que preferia ir ligando cada vez menos, pois ocupam demasiado tempo, precioso para o desenvolvimento de outras bem mais agradáveis, mas nem sempre tal é possível.

$\mathrm{Na}$ ótica gastronómica, prefere os pratos tradicionais, mais lineares, ou gosta de algo mais surpreendente? A frequência com que se dedica à cozinha costuma estar mais no verde ou no vermelho? A sua dieta é catalisada por produtos bio?

Na gastronomia gosto de pratos mais fora do tradicional, com mistura de sabores e também de culturas. Gosto da surpresa dos novos sabores e de novas experiências. A frequência com que me dedico à cozinha está no verde uma vez que é diária e nem sempre positiva pela repetição. Gosto de cozinhar, mas são as experiências com mais tempo ao fim de semana, para quem aparecer lá por casa, que mais me entusiasmam, pelo interesse nas novas receitas e sabores, onde frequentemente troco ingredientes pelo prazer de imaginar novas misturas (ao bom jeito de um químico que já "viveu" na bancada!) e consoante o que aparece à mão. E até agora, não tem havido reclamações!...

Produtos bio, pois... são bons catalisadores e nos últimos anos tenho usado e abusado deles...mas voltando à dieta, sim tento sempre que possível introduzi-los em quantidades estequiométricas ou mesmo em excesso.
Nos momentos em que sente possuir uma elevada intensidade de corrente negativa e prevê que pode obter um pico de potencial desânimo, o que faz para reverter o processo?

Mudo a direção do varrimento e se possível a uma maior velocidade... e espero que o processo seja reversível! Se isto não resultar, então respiro fundo e conto até dez (por vezes ajuda muito!). Depois tento avaliar a situação pelo lado positivo (pois há sempre um lado positivo em todas as situações, nem sempre é fácil é encontrá-lo!). E quando nada disto parece estar a resultar, saio da rotina e vou às compras, pois espairece a cabeça e alivia a bolsa, claro!

Diga-nos no que mais se revê, se possível com um breve comentário: corar ou descorar, acaso ou destino, coração ou razão.

Corar de vergonha perante certas atitudes que vejo nos políticos do meu país, perante as atrocidades que se vão cometendo pelo Mundo fora ... e pela sua impunidade;

Acaso, às vezes gosto de pensar que algumas coisas na minha vida se devem ao acaso e que por acaso, até têm terminado bem;

Coração, embora sem dúvida a razão seja muito mais prática e pragmática, mas sem o coração a vida deixa de ter sabor!...

Para lá da atividade docente e científica, a que situações da vida é que gostaria de aplicar os seguintes termos: reagir, descobrir, concluir.

Reagir às injustiças que vejo à minha volta e manter a capacidade de me indignar com elas;

Descobrir novos lugares que possuam a capacidade de deslumbrar, novos momentos e situações que me emocionem e novos compostos (porque não?);

Concluir... essa é mesmo muito difícil, concluir alguns projetos de vida que têm ficado precisamente para lá da atividade docente e científica.

Paulo Mendes pjgm@uevora.pt

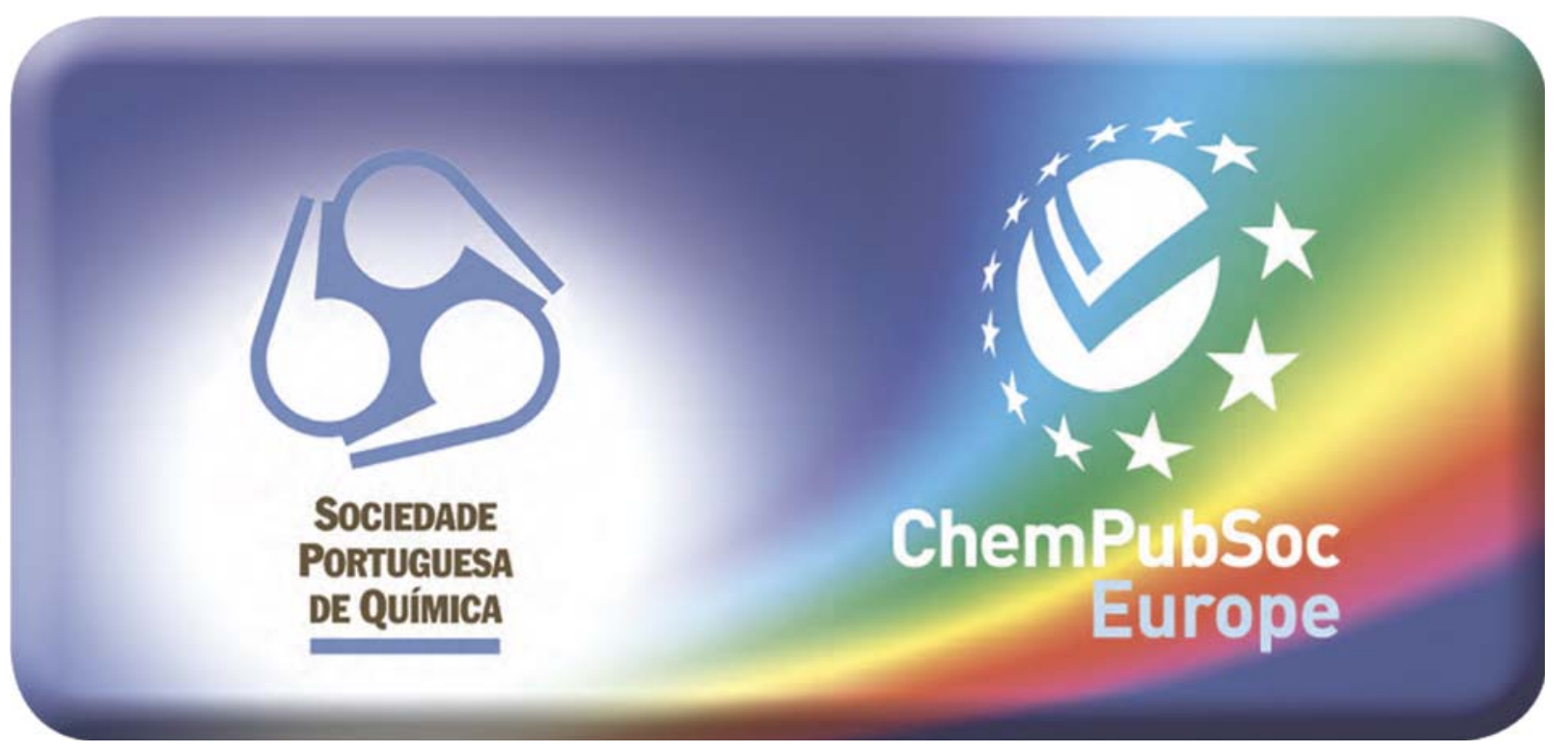

